\title{
Optimization of CASP-CUSUM Schemes Based on Truncated Hyper-Exponential Distribution
}

\author{
Narayana Murthy B. R ${ }^{1}$, Akhtar P. Md ${ }^{2}$ \\ ${ }^{1}$ Lecturer in Statistics Govt.College (Autonomous), Ananthapuramu, A.P., India . \\ ${ }^{2}$ Professor, Department of Statistics, S.K. University, Ananthapuramu, A.P., India.
}

\begin{abstract}
Acceptance sampling plans are introduced mainly to accept or reject the lots of finished products. There are several techniques available to control the quality. Some of the techniques are popularly used where testing involves destruction, for instance, in the manufacturing of crackers, bullets, batteries, bulbs and so on, it is impossible to go for $100 \%$ inspection. In this paper we optimized CASP-CUSUM Schemes based on the assumption that the continuous variable under consideration follows a Truncated Hyper-Exponential Distribution. The Hyper-Exponential Distribution is continuous distribution generally used in Life-time Analysis of products, particularly in estimating reliability by considering its distribution. Optimization of CASP-CUSUM Schemes is suggested based on numerical result obtained by changing the values of the parameters of the Hyper-Exponential distribution.
\end{abstract}

Keywords: CASP-CUSUM Schemes, type C, OC Curve, ARL, Truncated Hyper-Exponential Distribution.

\section{Introduction}

In this cut- throat competition various factors which will affect the quality and reliability of a product such as rapid evolution of new materials, components, processes, complexity of the product being manufactured, need to meet customers' demands such as availability, safety, warranty and require the full cooperation of all employees of an Organization manufacturing the product. In the past, the term 'quality' is defined in different dimensions, especially with regard to consumer point of view, system designer's point of view and so on. Durability, Safety, low-cost and the degree of satisfaction are the main characteristics which determine the quality of a product in Consumer's point of view. But in system designer's point of view the degree of profit and the degree of low cost productions are the major characteristics that determine the quality.

One of the most widely used qualities of control tools is the Acceptance Sampling Plans. Acceptance Sampling Plans determines the 'Sample Size' and Criteria for accepting or rejecting a product or batch based on the quality of a sample, using Statistical principles. Different types of techniques are employed by industries mainly in the manufacturing of Bullets, Crackers, Bulbs, and Batteries and so on, where $100 \%$ inspection is not possible. Sampling provides one rational means of verification that a production lot conforms to the requirements of technical specifications. 100\% inspection does not guarantee 100\% compliance and is too time consuming and costly. Rather than evaluating all items or products, a specified sample is taken, inspected or tested, and a decision is made about accepting or rejecting the entire production lot. Obviously, if the reliability of the product increases then the quality of the product will also increases, because in producer's point of view, the probability that an item or a machine or a product will survive for a longer period of time. It states that a better quality of a product. It can be evidently observed that the quality of the product depends on the functioning of the system. The quality of the product is usually deferred from time to time and also the quality defers from product to product in the same manufacturing process. For example in case of electric bulbs the durability of an electric bulb will changes from bulb to bulb. Thus quality is the random phenomena.

Hawkins, D.M. [3] proposed a fast accurate approximation for ARL's of a CUSUM Control Charts. This approximation can be used to evaluate the ARL's for specific parameter values and the out of control ARL's of location and scale CUSUM Charts. Lonnie. C. Vance, [6] considered Average Run Length of cumulative Sum Control Charts for controlling for normal means and to determine the parameters of a CUSUM Chart. To determine the parameter of CUSUM Chart the acceptable and rejectable quality levels along with the desired respective ARL's are considered.

Vardeman.S, Di-ou Ray [9] was introduced CUSUM control charts under the restriction that the values regard to quality are exponentially distributed. Further the phenomena under study is the occurrence of rate of rare events and the inter arrival times for a homogenous poison process are identically independently distributed exponential random variables. Kakoty.S. Chakraborthy A.B. [5] proposed CASP - CUSUM charts under the assumption that the variable under study follows a Truncated Normal distribution. Generally truncated distributions are employed in many practical phenomena where there is a constraint on the lower and upper limits of the variable under study. For example, in the production of engineering items, the sorting procedure 
eliminates items above or below designated tolerance limits. It is worthwhile to note that any continuous variable be the first approximated as an exponential variable.

YI Dai, Yunzhao Luo, Zhonghua, Li and Zhaojun Wang [10] recommended a more generalized multivariate CUSUM (MCUSUM) control charts which are usually called adaptive MCUSUM Control Charts which not only operate without any pre-knowledge about the process shift, but also achieve an overall approximately optimal performance at each point in a broader range of mean shifts. Finally it is concluded by addressing some relevant issues such as super imposing Shewart Control Limit on their AMCUSUM Chart will perform more efficiently for large mean shifts just like combine Shewart CUSUM Charts.

Muhammad Riaz, Nasir Abbas and Ronald J.M.M Does [7] proposed two Runs rules schemes for the CUSUM Charts. The performance of the CUSUM and EWMA Charts are compared with the usual CUSUM and weighted CUSUM, the first initial response CUSUM compared with usual EWMA Schemes. This comparison stated that the proposed schemes perform better for small and moderate shifts. Akthar P.Md and Sarma K.L.A.P [1] proposed an optimization of CASP-CUSUM Schemes based on truncated two parametric Gamma distribution and evaluated $\mathrm{L}(\mathrm{O}) \mathrm{L}^{\prime}(\mathrm{O})$ and Probability of Acceptance and also optimized CASP-CUSUM Schemes based on numerical results. In the present paper it is proposed CASP-CUSUM Charts when the variable under study follows truncated Hyper-Exponential Distribution. Thus it is more worthwhile to study some interesting characteristics of this distribution.

\section{Hyper-Exponential Distribution}

The concept of Hyperness came from the idea of mixture of distributions. The natural motivation for mixing two distributions came from the basic concept of conditional probability density / mass functions. The mixture of distributions is nothing but the generalization of conditional probability $\mathrm{P}(\mathrm{X} / \mathrm{Y})$ where $\mathrm{X}$ is the discrete random variable and $\mathrm{Y}$ is continuous random variable or vise-versa. such mixture distributions arise in many practical problems especially in reliability theory.

\section{Truncated Hyper-Exponential Distribution}

Definition: The random variable $\mathrm{X}$ is said to follow a truncated Hyper-Exponential Distribution as:

$$
P(X=X)=F_{B}(X)=\frac{a_{1} \lambda_{1} e^{-\lambda_{1}^{x}}+a_{2} \lambda_{2} e^{-\lambda_{2}^{x}}}{1-\left\{a_{1} e^{-\lambda_{1}^{B}}+a_{2} e^{-\lambda_{2}^{B}}\right\}} \quad 0 \leq \mathrm{X} \leq \mathrm{B}
$$

$=0$, otherwise.

Where ' $\mathrm{B}$ ' is the truncation point of the Hyper-Exponential Distribution.

The Hyper-Exponential Distribution very flexible for modeling of life time of any product, and used for the life modeling in reliability analysis, life testing problems and accepting sampling plans. This distribution has been experienced in many applications such as communication, engineering and life testing. Hyper-Exponential Distribution very flexible for modeling failure rate by choosing an appropriate value of the parameter.

Hyper-Exponential Distribution is a member of continuous probability distribution. It is often used in wind speed, energy, physics, communication and lifetime analysis and quality inspection. For example, it is used to model scattered signals that reach a receiver by multiple paths.

\section{IDescription Of The Plan And Type-C Oc Curve}

Beattie [2] has suggested the method for constructing the continuous acceptance sampling plan. The procedure, suggested by him consists of a chosen decision interval namely, "Return interval" with the length h', above the decision line is taken. We plot on the chart the sum $\mathrm{Sm}=\sum\left(X_{i}-k\right) X_{i}{ }^{\prime} s(i=1,2,3 \ldots)$ are distributed independently and $\mathrm{k}$ is the reference value. If the sum lies in the area of normal chart, the product is accepted and if it lies in the of the return chart, the product is rejected, subject to the following assumptions.

1. When the recently plotted point on the chart touches the decision line, then the next point to be plotted at the maximum, i.e., $\mathrm{h}+\mathrm{h}$ '.

2. When the decision line is reached or crossed from above, the next point on the chart is to be plotted from the baseline.

When the CUSUM falls in the return chart, network or a change of specification may be employed rather than outright rejection.

The procedure in brief is given below.

1. Start plotting the CUSUM at 0. 
2. The product is accepted when $\mathrm{S}_{\mathrm{m}}=\sum\left(X_{i}-k\right)<h$; when $\mathrm{S}_{\mathrm{m}}<0$, return cumulative to 0 .

3. When $\mathrm{h}<\mathrm{S}_{\mathrm{m}}<h+h^{\prime}$ the product is rejected: when $\mathrm{S}_{\mathrm{m}}$ crosses h, i.e., when $\mathrm{S}_{\mathrm{m}}>h+h^{\prime}$ and Continue rejecting product until $\mathrm{S}_{\mathrm{m}}>h+h^{\prime}$ return cumulative to $h+h^{\prime}$.

The Type - C, OC function, which is defined as the probability of acceptance of an item as a function of incoming quality, when sampling rate is same in acceptance and rejection regions. Then the probability of acceptance $\mathrm{P}(\mathrm{A})$ is given by

$$
P(A)=\frac{L(0)}{L(0)+L^{\prime}(0)}
$$

Where $L(0)=$ Average Run Length in acceptance zone and

$L^{\prime}(0)=$ Average Run Length in rejection zone.

Page, E.S [8] has introduced the formulae for $L(0)$ and $L^{\prime}(0)$ as

$$
\begin{aligned}
& L(0)=\frac{N(0)}{1-P(0)} \\
& L^{\prime}(0)=\frac{N^{\prime}(0)}{1-P^{\prime}(0)}
\end{aligned}
$$

Where $\mathrm{P}(0)=$ Probability for the test starting from zero on the normal chart,

$\mathrm{N}(0)=$ ASN for the test starting from zero on the normal chart,

$P^{\prime}(0)=$ Probability for the test on the return chart and

$N^{\prime}(0)=$ ASN for the test on the return chart.

He further obtained integral equations for the quantities

$\mathrm{P}(0), \mathrm{N}(0), P^{\prime}(0), N^{\prime}(0)$ as follows :

$P(z)=F(k-z)+\int_{0}^{h} p(y) f(y+k-z) d y$,

$N(z)=1+\int_{0}^{h} N(y) f(y+k-z) d y$,

$P^{\prime}(z)=\int_{k+z}^{B} f(y) d y+\int_{0}^{h} P^{\prime}(y) f(-y+k+z) d y$

$N^{\prime}(z)=1+\int_{0}^{h} N^{\prime}(y) f(-y+k+z) d y$,

$F(x)=1+\int_{A}^{h} f(x) d x$ :

$F(k-z)=1+\int_{A}^{k-z} f(y) d y$,

and $\mathrm{z}$ is the distance of the starting of the test in the normal chart from zero. 


\section{Method Of Solution}

We first express the integral equation (4.4) in the form

$$
\begin{gathered}
\mathrm{F}(\mathrm{x})=\mathrm{Q}(\mathrm{x})+\int_{c}^{d} R(x, t) F(t) d t \\
\text { Where } \mathrm{F}(\mathrm{x})=\mathrm{P}(\mathrm{z}) \\
\mathrm{Q}(\mathrm{x})=\mathrm{F}(\mathrm{k}-\mathrm{z}) \\
\mathrm{R}(\mathrm{x}, \mathrm{t})=\mathrm{f}(\mathrm{y}+\mathrm{k}-\mathrm{z})
\end{gathered}
$$

Let the integral $\mathrm{I}=\int_{c}^{d} f(x) d x$ be transformed to

$$
I=\frac{d-c}{2} \int_{c}^{d} f(y) d y=\frac{d-c}{2} \sum a_{i} f\left(t_{i}\right)
$$

Where $\mathrm{y}=\frac{2 x-(c-d)}{d-c}$ where $\mathrm{a}_{\mathrm{i}}$ 's and $\mathrm{t}_{\mathrm{i}}$ 's respectively the weight factor and abscissa for the GaussChibyshev polynomial, given in Jain M.K. and et al [4] using (5.1) and (5.2), (4.4) can be written as

$$
\mathrm{F}(\mathrm{x})=\mathrm{Q}(\mathrm{x}) \quad \frac{d-c}{2} \sum a_{i} R\left(x, t_{i}\right) F\left(t_{i}\right)
$$

Since equation (3.3) should be valid for all values of $x$ in the interval (c,d), it must be true for $x=t_{i} . i=0(1) n$ then obtain

$$
\begin{gathered}
\mathrm{F}\left(\mathrm{t}_{\mathrm{i}}\right)=\mathrm{Q}\left(\mathrm{t}_{\mathrm{i}}\right)+\frac{d-c}{2} \sum a_{i} R\left(t_{j}, t_{i}\right) F\left(t_{i}\right) \\
\mathrm{j}=0(1) \mathrm{n}
\end{gathered}
$$

'Substituting

$\mathrm{F}\left(\mathrm{t}_{\mathrm{i}}\right)=\mathrm{F}_{\mathrm{i}}, \mathrm{Q}\left(\mathrm{t}_{\mathrm{i}}\right)=\mathrm{Q}_{\mathrm{i}}, \mathrm{i}-0(1) \mathrm{n}$, in (2.4.4), we get

$$
\begin{aligned}
& \left.F_{o}=Q_{o}+\frac{d-c}{2}\left[a_{o} R\left(t_{o}, t_{o}\right) F_{o}+a_{1} R\left(t_{0}, t_{1}\right) F_{1}+\ldots a_{n} R\left(t_{0}, t_{n}\right) F_{n}\right)\right] \\
& \left.F_{1}=Q_{1}+\frac{d-c}{2}\left[a_{o} R\left(t_{1}, t_{o}\right) F_{o}+a_{1} R\left(t_{1}, t_{1}\right) F_{1}+\ldots a_{n} R\left(t_{1}, t_{n}\right) F_{n}\right)\right]
\end{aligned}
$$

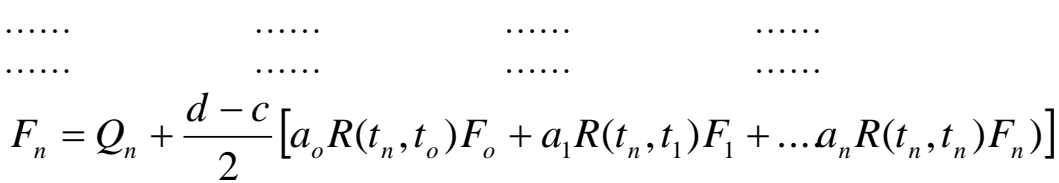

In the system of equations except $F_{i}, i=0,1 \ldots n$ are known and hence can be solved for $F_{i}$. We solve the system of equations by the method of Iteration. For this we write the system (5.5) as

$$
\begin{aligned}
& \left.\left[1-T a_{0} R\left(t_{o}, t_{0}\right)\right] F_{0}=Q_{0}+T\left[a_{o} R\left(t_{0}, t_{o}\right) F_{o}+a_{1} R\left(t_{0}, t_{1}\right) F_{1}+\ldots a_{n} R\left(t_{0}, t_{n}\right) F_{n}\right)\right] \\
& \left.\left[1-T a_{1} R\left(t_{1}, t_{1}\right)\right] F_{1}=Q_{1}+T\left[a_{0} R\left(t_{1}, t_{o}\right) F_{o}+a_{1} R\left(t_{1}, t_{1}\right) F_{1}+\ldots a_{n} R\left(t_{1}, t_{n}\right) F_{n}\right)\right] \\
& \begin{array}{lccc}
\ldots \ldots & \ldots \ldots & \ldots \ldots \\
\ldots \ldots & \ldots \ldots & \ldots \ldots \\
{\left[1-T a_{n} R\left(t_{n}, t_{n}\right)\right] F_{n}=} & \left.Q_{n}+T\left[a_{o} R\left(t_{n}, t_{o}\right) F_{o}+a_{1} R\left(t_{n}, t_{1}\right) F_{1}+\ldots a_{n} R\left(t_{n}, t_{n}\right) F_{n}\right)\right]
\end{array}
\end{aligned}
$$

Where $T=\frac{d-c}{2}$. 
To start the Iteration process, let us put $\mathrm{F} 1=\mathrm{F} 2=\ldots . \mathrm{Fn}=0$ in the first equation of (5.6), we then obtain a rough value of $\mathrm{Fo}$. Putting this value of $\mathrm{Fo}$ and $\mathrm{F} 2=\mathrm{F}_{3} \ldots . . \mathrm{Fn}=0$ in the second equation, we get a rough value $F_{1}$ and so on. This gives the first set of values $F_{i}, \quad i=0,1,2, \ldots \ldots \ldots, n$ which are just the refined values of $\mathrm{Fi}, \mathrm{i}=0,1,2, \ldots \ldots, \mathrm{n}$. The process is continued until two consecutive sets of values are obtained up to a certain degree of accuracy. In the similar way solutions $\mathrm{P}^{\prime}(0), \mathrm{N}(0), \mathrm{N}^{\prime}(0)$ can be obtained.

VI. Computation Of Arl's \& P (A)

We developed computer programs to solve equations (5.1 to 5.6) and get the following tables.

\begin{tabular}{|c|c|c|c|c|c|c|c|}
\hline TABLE - 6 & $\lambda_{1}=0.1, \lambda_{2}=0$ & $\mathrm{k}=1, \mathrm{~h}=0.25$ & $=0.25$ & TABLE -6 & $2 \lambda_{1}=0.1, \lambda_{2}=$ & $\mathrm{k}=1.5, \mathrm{~h}=0.2$ & $5, h^{\prime}=0.25$ \\
\hline 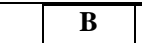 & $\mathbf{L}(\mathbf{0})$ & $\mathbf{L}^{\prime}(\mathbf{0})$ & $\mathbf{P}(\mathrm{A})$ & \begin{tabular}{l|l|l} 
& B \\
\end{tabular} & $\mathbf{L}(\mathbf{0})$ & $L^{\prime}(\mathbf{0})$ & \begin{tabular}{l|l}
$\mathbf{P}(\mathbf{A})$ \\
\end{tabular} \\
\hline 1.7 & 1.08723 & 1.1398094 & 0.4881945 & 2.2 & 1.57848 & 1.111001? & $\mathbf{0 . 5 8 6 9 0 7 9}$ \\
\hline 1.6 & 1.11500 & 1.1428208 & 0.4938388 & 2.1 & 1.68996 & 1.1169968 & 0.6020612 \\
\hline 1.5 & 1.15560 & 1.1425617 & 0.5028366 & 20 & 184671 & & 06218184 \\
\hline 1.4 & 1.21816 & 1.1366948 & 0.5172971 & 2.0 & 1.84671 & 1.123142 & 0.6218184 \\
\hline 1.3 & 1.32231 & 1.1215484 & 0.5410739 & 1.9 & 2.08179 & 1.1292478 & 0.6483229 \\
\hline 1.2 & 1.51915 & 1.0915695 & 0.5818897 & 1.8 & 2.47038 & 1.134985 & 0.6851953 \\
\hline 1.1 & 1.99764 & 1.0389469 & 0.6578571 & 1.7 & 3.22784 & 1.139809 & 0.7390336 \\
\hline 1.0 & $4 \mathbf{4 . 5 8 5 5 8}$ & 0.9541929 & 0.8277560 & 1.6 & 5.32096 & 1.142820 & 0.8231962 \\
\hline & & & & 1.5 & 36.7536 & 1.142561 & 0.9693007 \\
\hline TAF & $-6.3 \lambda_{1}=0$. & $=0.3, k=1.5$ & $\mathrm{n}=0.5, \mathrm{~h}^{\prime}=0.5$ & TABI & $E-6.4 \lambda_{1}=0$ & $\lambda_{2}=0.3, \mathrm{k}=2, \mathrm{~h}=$ & $=0.25, h^{\prime}=0.25$ \\
\hline B & $\mathbf{L}(\mathbf{0})$ & $\mathbf{L}^{\prime}(\mathbf{0})$ & $\mathbf{P}(\mathbf{A})$ & \begin{tabular}{l|l} 
B & \\
\end{tabular} & $\mathbf{L}(\mathbf{0})$ & $L^{\prime}(\mathbf{0})$ & $\mathbf{P}(\mathbf{A})$ \\
\hline & 1.20863 & 1.1570265 & 0.5109076 & 2.7 & 2.07888 & 1.0855500 & $\begin{array}{l}\mathbf{0 . 6 5 6 9 5 2} \\
\end{array}$ \\
\hline 2.2 & $1.2000 \mathrm{~S}$ & 1.1570205 & $0.51090 / 0$ & 2.6 & 2.27371 & 1.0899833 & 0.675956 \\
\hline 2.1 & 1.25809 & 1.1571751 & 0.5208908 & 2.5 & 2.54659 & 1.0947425 & 0.699356 \\
\hline 2.0 & 1.32686 & 1.1548976 & 1.5346457 & 2.4 & 2.95494 & 1.0998368 & 0.728755 \\
\hline 1.9 & 1.42737 & 1.1491522 & 0.5539916 & 2.3 & 3.63068 & 1.1052638 & 0.766622 \\
\hline 1.8 & 1.58525 & 1.1385281 & $\mathbf{0 . 5 8 2 0 0 4 4}$ & 2.2 & 4.95839 & 1.1110017 & 0.816950 \\
\hline 1.7 & 1.86335 & $\mathbf{1 . 1 2 1 1 5 3 7}$ & 0.6243420 & 2.1 & 8.73665 & 1.1169968 & 0.886641 \\
\hline 1.6 & 2.46902 & 1.0946261 & 0.6928352 & 2.0 & 98.43071 & 1.1231424 & 0.988718 \\
\hline 1.5 & 4.74858 & 1.0560194 & 0.8180721 & & & & \\
\hline TAI & $E-6.5 \lambda_{1}=0$ & $\lambda_{2}=0.3, \mathrm{k}=2$, & $=0.5, h^{\prime}=0.5$ & TABLE -6 & $6 \lambda_{1}=0.1, \lambda_{2}=$ & $\mathrm{k}=2, \mathrm{~h}=\mathbf{0 . 7 5}$ & $h^{\prime}=0.75$ \\
\hline B & $L(\mathbf{0})$ & $L^{\prime}(\mathbf{0})$ & $\mathbf{P}(\mathbf{A})$ & \begin{tabular}{|l|l|} 
& B \\
\end{tabular} & $\mathbf{L}(\mathbf{0})$ & \begin{tabular}{l|l}
$\mathbf{L}^{\prime}(\mathbf{0})$ \\
\end{tabular} & $\mathbf{P}(\mathbf{A})$ \\
\hline 2.7 & 1.71667 & 1.1401600 & 0.6009009 & 2.7 & 1.39392 & 1.1632582 & 0.5451009 \\
\hline 2.6 & 1.84855 & 1.1445107 & 0.6176121 & 2.6 & 1.47137 & 1.1634763 & 0.5584272 \\
\hline 2.5 & 2.03134 & 1.1486157 & 0.6387948 & 2.5 & 1.57655 & 1.1622776 & 0.5756289 \\
\hline 2.4 & 2.30029 & 1.1522760 & 0.6662556 & 2.4 & 1.72649 & $\mathbf{1 . 1 5 9 1 9 1 5}$ & $\mathbf{0 . 5 9 8 2 9 5 5}$ \\
\hline 2.3 & 2.73271 & 1.1552107 & 0.7028720 & 2.3 & 1.95562 & 1.1536164 & 0.6289712 \\
\hline 2.2 & 3.53703 & 1.1570265 & 0.7535126 & 2.2 & 2.34552 & 1.1447910 & 0.6720089 \\
\hline 2.1 & 5.53581 & 1.1571751 & 0.6271064 & 2.1 & 3.14831 & 1.1317651 & $\mathbf{0 . 7 3 5 5 7 3 4}$ \\
\hline 2.0 & 18.75014 & 1.1548976 & 0.9419796 & 2.0 & 5.72433 & 1.1133775 & 0.8371710 \\
\hline TAB & $-6.7 \lambda_{1}=0$ & ${ }_{2}=0.5, k=1,1$ & $=0.25, h^{\prime}=0.25$ & TABL & $E-6.8 \lambda_{1}=0$. & ${ }_{2}=0.5, \mathrm{k}=1.5, \mathrm{~h}$ & $=0.25, h^{\prime}=0.25$ \\
\hline B & $L(0)$ & $L^{\prime}(\mathbf{0})$ & $\mathbf{P}(\mathbf{A})$ & $\mathbf{B}$ & $\mathbf{L}(\mathbf{0})$ & $\mathbf{L}^{\prime}(\mathbf{0})$ & $\mathbf{P}(\mathbf{A})$ \\
\hline 1.7 & 0.99686 & 1.1143477 & 0.4721760 & 2.2 & 1.49367 & 1.1011709 & $\begin{array}{l}0.5756308 \\
\end{array}$ \\
\hline 1.6 & 1.01484 & 1.1120634 & 0.4771454 & 2.1 & 1.59417 & 1.1050587 & 0.5906028 \\
\hline 1.5 & 1.04239 & 1.1054238 & 0.4853249 & 2.0 & 1.73418 & 1.1086931 & $\mathbf{0 . 6 1 0 0 1 0 3}$ \\
\hline 1.4 & 1.08654 & 1.0919622 & $\begin{array}{l}0.4987561 \\
\end{array}$ & 1.9 & 1.94264 & 1.1117891 & $\mathbf{0 . 6 3 6 0 0 7 7}$ \\
\hline 1.3 & 1.16245 & 1.0680190 & 0.5211682 & 1.8 & 2.28433 & 1.1139029 & 0.6722115 \\
\hline 1.2 & 1.30936 & 1.0284005 & 0.5600924 & 1.7 & 2.94096 & 1.1143477 & 0.7252125 \\
\hline 1.1 & 1.67160 & 0.9663516 & 0.6336738 & 1.6 & 4.69211 & 1.1120634 & $\mathbf{0 . 8 0 8 4 0 2 7}$ \\
\hline 1.0 & 3.62463 & 0.8744303 & 0.8056417 & 1.5 & 22.78117 & 1.1054238 & 0.9537220 \\
\hline TAB & $-6.9 \lambda_{1}=0$. & $=0.5, \mathrm{k}=1.5$ & $=0.5, h^{\prime}=0.5$ & TAB & $-6.10 \lambda_{1}=$ & $\lambda_{2}=0.5, \mathrm{k}=2$, & $.25, h^{\prime}=0.25$ \\
\hline
\end{tabular}




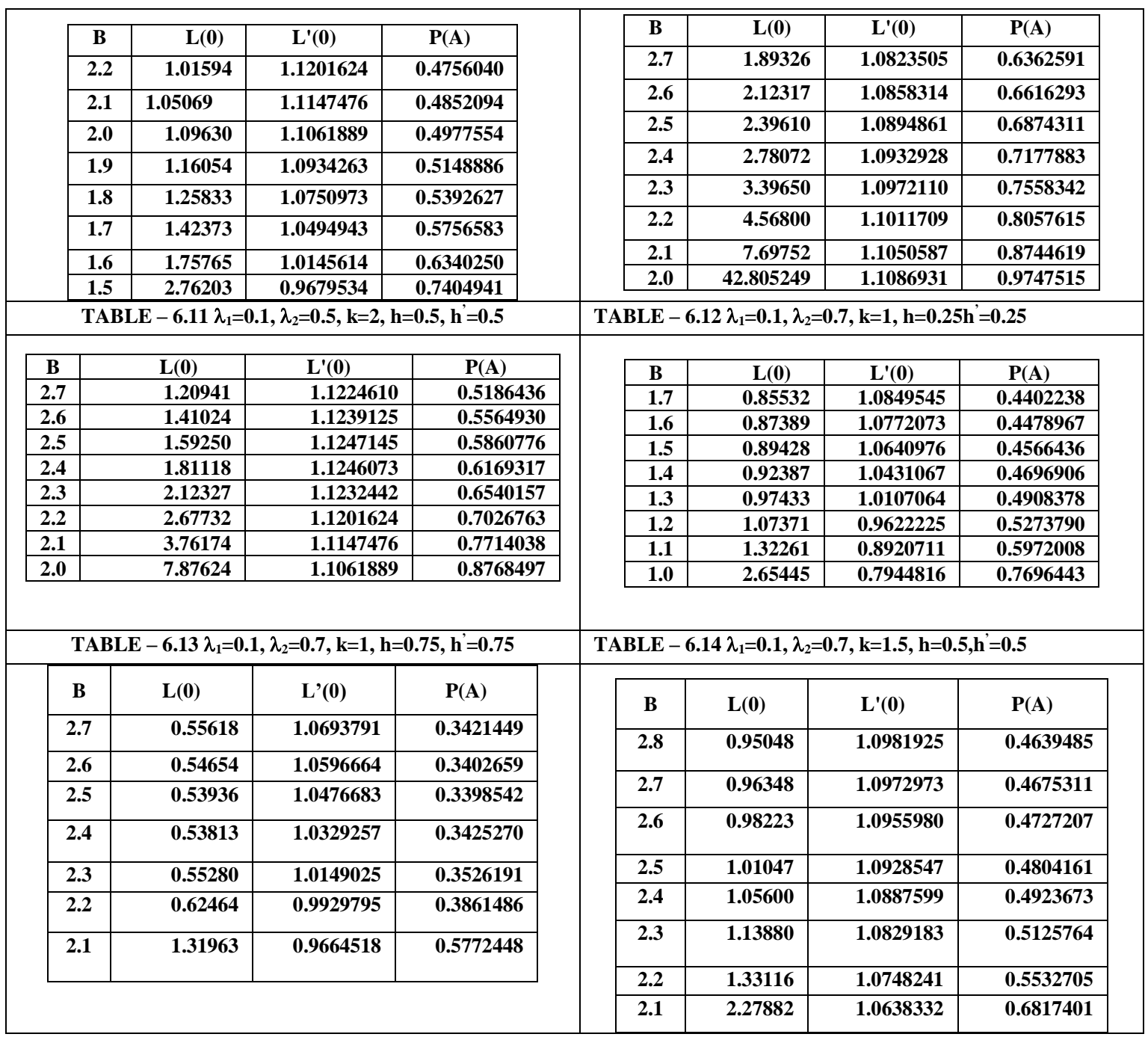

\section{Conclusions}

For the hypothetical values of the parameters $\lambda_{1}, \lambda_{2}, \mathbf{k}, \mathbf{h}, \&$ h' given at the top of each table, We determine optimum truncated point $\mathrm{B}$ at which $\mathrm{P}(\mathrm{A})$ the probability of accepting an item is maximum and also obtained ARL's values which represents the acceptance zone $L(O)$ and rejection zone $L^{\prime}(O)$ values. The values of truncated point $\mathrm{B}$ of random variable $\mathrm{X}, L(O), L^{\prime}(O)$ and the values for Type - C OC Curve, i.e. $\mathrm{P}$ (A) are given in columns I, II, III and IV respectively.

From the above tables 6.1 to 6.14 we made the following conclusions

(i) By observing the above tables the values of $h$,h' increases then related values of $\mathrm{L}(0)$ decreases. So the sizes of accepted and rejected zones and $\mathrm{L}(0)$ are inversely related.

(ii) By observing the above tables the values of $h$, h' increases then related values of $\mathrm{P}(\mathrm{A})$ decreases. So the sizes of accepted and rejected zones and $\mathrm{P}(\mathrm{A})$ are inversely related.

(iii) By observing the above tables the reference value $\mathrm{K}$ increases then $\mathrm{L}(0)$ increases. So, reference value and $\mathrm{L}(0)$ are positively related.

(iv) By observing the above tables the reference value $\mathrm{K}$ increases then $\mathrm{P}(\mathrm{A})$ increases. So, reference value and $\mathrm{P}(\mathrm{A})$ are positively related.

(v) By observing the above table we found that the value of parameter of Hyper-Exponential distribution increases then $\mathrm{P}(\mathrm{A})$ is also increases. So the parameters of Hyper-Exponential distribution and $\mathrm{P}(\mathrm{A})$ are positively related.

(vi) The various relations exhibited among the ARL's and Type-C OC Curves with the parameters of the CASP-CUSUM based on the above table 6.1 to 6.14 are observed from the following table No.7.1. 
Table -7.1

\begin{tabular}{|c|c|c|c|c|c|c|c|c|}
\hline B & $\lambda_{1}$ & $\lambda_{2}$ & $\mathbf{k}$ & h & h' & L (O) & $\mathbf{L}(\mathbf{O})$ & $\mathbf{P}(\mathbf{A})$ \\
\hline 1.0 & 0.1 & 0.3 & 1 & 0.25 & 0.25 & 4.58558 & 0.9541929 & 0.8277560 \\
\hline 1.5 & 0.1 & 0.3 & 1.5 & 0.25 & 0.25 & 36.07536 & 1.1425617 & 0.9693007 \\
\hline 1.5 & 0.1 & 0.3 & 1.5 & 0.5 & 0.5 & 4.74858 & 1.0560194 & 0.8180721 \\
\hline 2.0 & 0.1 & 0.3 & 2.0 & 0.25 & 0.25 & 98.43071 & 1.1231424 & 0.9887183 \\
\hline 2.0 & 0.1 & 0.3 & 2.0 & 0.5 & 0.5 & 18.75014 & $\mathbf{1 . 1 5 4 8 9 7 6}$ & 0.9419796 \\
\hline 2.0 & 0.1 & 0.3 & 2.0 & 0.75 & 0.75 & 5.72433 & 1.1133775 & $\mathbf{0 . 8 3 7 1 7 1 0}$ \\
\hline 1.0 & 0.1 & 0.5 & 1.0 & 0.25 & 0.25 & 3.62463 & 0.8744303 & 0.8056417 \\
\hline 1.5 & 0.1 & 0.5 & 1.5 & 0.25 & 0.25 & 22.78117 & 1.1054238 & 0.9537220 \\
\hline 1.5 & 0.1 & 0.5 & 1.5 & 0.50 & 0.50 & 2.76203 & 0.9679534 & 0.7404941 \\
\hline 2.0 & 0.1 & 0.5 & 2.0 & 0.25 & 0.25 & 42.80249 & 1.1086931 & 0.9747515 \\
\hline 2.0 & 0.1 & 0.5 & 2.0 & 0.5 & 0.5 & 7.87624 & 1.1061889 & 0.8768497 \\
\hline 1.0 & 0.1 & 0.7 & 1.0 & 0.25 & 0.25 & 2.65445 & 0.7944816 & 0.7696443 \\
\hline 2.1 & 0.1 & 0.7 & 1.0 & 0.75 & 0.75 & 1.31963 & 0.9664518 & 0.5772448 \\
\hline 2.1 & 0.1 & 0.7 & 1.5 & 0.5 & 0.5 & 2.27882 & 1.0638332 & 0.6817401 \\
\hline
\end{tabular}

By observing the above table the values of $\mathrm{L}(\mathrm{O})$ and $\mathrm{P}(\mathrm{A})$, the optimum CASP-CUSUM as

$$
\left[\begin{array}{l}
\mathrm{B}=2.0 \\
\lambda 1=0.1 \\
\lambda 2=0.3 \\
\mathrm{k}=2 \\
\mathrm{~h}=0.25 \\
\mathrm{~h}^{\prime}=0.25
\end{array}\right]
$$

And the value of $\mathrm{P}$ (A) $\mathbf{0 . 9 8 8 7 1 8 3}$ respectively.

\section{References}

[1]. Akhtar P.Md.and Sarma K.L.A.P.(2004) "Optimization of CASP-CUSUM Schemes based on Truncated Gamma Distribution." Bulletin of pure and applied sciences, Vol-23E No.2, PP.215-223.

[2]. Beattie,B.W.,(1962), “ A Continuous Acceptance Sampling Procedure based upon a Cumulative Sums Chart for number of defectives", Applied Stat5atistics, Vol. 11, No.2, pp. 137-147.

[3]. Hawkins, D.M. , (1992), “A Fast Accurate Approximation for Average Run Lengths of CUSUM Control Charts, Journal of Quality Technology", Vol. 24, No.1, pp. 37-43.

[4]. Jain,M.K. ,Iyengar,S.R.K. and Jain, R.K. "Numerical Methods of Scientific and Engineering Computations", Wiley Eastern Ltd., New Delhi.

[5]. Kakoty, S and Chakraborthy, A.B., (1990), "A Continuous Acceptance Sampling Plan for truncated Normal distribution based on Cumulative Sums", Journal of National Institution for Quality and Reliability, Vol.2, No. 1, pp. 15-18.

[6]. Lonnie. C. Vance, (1986), "Average Run Length of CUSUM Charts for Controlling Normal means. Journal of Quality Technology”, Vol.18, pp. 189-193.

[7]. Muhammad Riaz, Nasir Abbas and Ronald, J.M.M. Does, (2011) "Quality and Reliability Engineering International”, Vol.27, 415424.

[8]. Page, E.S.,(1954), “Continuous Inspection Schemes”, Biometrika, Vol .XLI, pp .104- 114.

[9]. Vardeman,S. and Di-ou Ray, (1985), "Average Run Lenghts for CUSUM schemes where observations are Exponentially Distributed, Technometrics", Vol.27, No.2, pp. 145-150.

[10]. Yi Dai, Yunzhao Luo, Zhonghua Li, and Zhaojun Wang, LPMC and School of Mathematical Sciences, Nankai University, Tianjin, P.R.China.

Narayana Murthy B. R. "Optimization of CASP-CUSUM Schemes Based on Truncated HyperExponential Distribution." IOSR Journal of Mathematics (IOSR-JM) 3.3 (2017): 24-30. 